\title{
Is de novo stress incontinence after sacrocolpopexy related to anatomical changes and surgical approach? Response to comments by van der Weiden and Withagen
}

\author{
Edgar L. LeClaire • Lieschen H. Quiroz
}

Published online: 5 March 2015

(C) The International Urogynecological Association 2015

Dear Editor,

We are grateful to van der Weiden and Withagen for sharing their findings [1].

We observed an overall de novo SUI rate of almost $30 \%$ among our cohort of open and minimally invasive sacrocolpopexy (SCP) patients with negative preoperative prolapse reduction stress testing (PRST) [2]. In our statistical model, we noted a clear specific relationship between de novo stress urinary incontinence (SUI) and Aa reduction magnitude, regardless of surgical route. Patients with a high $(6 \mathrm{~cm} \geq \Delta \mathrm{Aa}<4 \mathrm{~cm})$ Aa reduction magnitude were at the highest risk. These findings warrant careful attention to anterior reduction during PRST. False-negative testing may reflect a mismatch between instrumented Aa reduction at PRST and surgical Aa reduction at SCP. Effort should be made to closely match reduction at testing with anticipated surgical reduction, especially when the expected Aa reduction magnitude from surgery is $>4 \mathrm{~cm}$. Thus, we would agree with cautious and consistent anterior prolapse correction during both PRST and SCP.

Conflicts of interest Neither author has any conflict of interest.

\section{References}

1. Van der Weiden RMF, Withagen MIJ (2015) Comments on LeClaire et al:: is de novo stress incontinence after sacrocolpopexy related to anatomical changes and surgical approach? Int Urogynecol J. doi: 10. 1007/s00192-015-2657-1

2. LeClaire EL, Mukati MS, Juarez D, White D, Quiroz LH (2014) Is de novo stress incontinence after sacrocolpopexy related to anatomical changes and surgical approach? Int Urogynecol J 25:1201-1206. doi:10.1007/s00192-014-2366-1

\footnotetext{
E. L. LeClaire $(\bowtie)$

Department of Obstetrics and Gynecology, Division of Female Pelvic Medicine and Reconstructive Surgery, University of Kansas School of Medicine-Wichita, 550 North Hillside, Wichita, KS 67214 , USA

e-mail: edgar.leclaire@gmail.com

L. H. Quiroz

Division of Female Pelvic Medicine and Reconstructive Surgery, University of Oklahoma Health Sciences Center, 920 SL Young Blvd, Room WP 2410, Oklahoma City, OK 73104, USA
} 